\title{
Territorios, margen y los mapas de la fragmentación. La creación de sujetos de desarrollo y sujetos de marginalidad ${ }^{1}$
}

\section{Territories, margin and fragmentation maps. The creation of subjects of development and subjects of marginality}

Recibido: 07 de abril de 2016 - Revisado: 22 de julio de 2016 - Aceptado: 13 de septiembre de 2016.

\author{
Carlos Alberto Dávila Cruz ${ }^{2}$ \\ Claudia Alexandra Munévar Quintero ${ }^{3}$ \\ Rodrigo Giraldo Quintero ${ }^{4}$
}

\section{Resumen}

El artículo tiene como objetivo problematizar las condiciones de los sujetos que están sometidos a contextos socioeconómicos a través de la dicotomía desarrollo/progreso. Para ello, en primer lugar, se conceptualizó sobre las diferentes posiciones teóricas sobre el territorio a partir de sus concepciones físicas, sociales y antropológicas. En segundo lugar, se problematizó sobre la teoría de progreso y crecimiento gestada por el modelo de desarrollo, la cual ha reconfigurado la noción de "sujetos de derechos" para emerger de sí "sujetos de desarrollo". Finalmente, se plantea la existencia de escenarios de vulnerabilidad y marginalidad, que dan origen a sujetos marginales, producto de los límites y los fragmentos de los territorios y los márgenes que los deshumanizan.

\section{Palabras clave}

Territorio, desarrollo, vulnerabilidad, marginalidad, sujetos.

\begin{abstract}
The article aims to problematize the conditions of subjects who are subjected to socioeconomic contexts through the development / progress dichotomy. For this, in the first place, it was conceptualized on the different theoretical positions on the territory from its physical, social and anthropological conceptions. Secondly, the theory of progress and growth developed by the development model has been problematized, which has reconfigured the notion of "subjects of rights" to emerge from themselves "subjects of development". Finally, there are scenarios of vulnerability and marginality, which give rise to marginal subjects, product of the limits and fragments of the territories and the margins that dehumanize them.
\end{abstract}

\section{Keywords}

Territory, development, vulnerability, marginality, subjects.
1 El presente artículo se deriva del proyecto de investigación titulado: "Conflictos y movimientos sociales de jóvenes en contextos de vulnerabilidad en la eco-región Eje Cafetero: hacía un proceso de constitucionalismo popular". Financiado por la Universidad de Manizales, Manizales, Colombia.

${ }^{2}$ Abogado. Docente investigador. Facultad de Ciencias Sociales y Humanas de la Universidad de Manizales. Magíster en Derecho. Doctorando en Estudios Territoriales de la Universidad de Caldas.

Correo electrónico: cadavilac@umanizales.edu.co

3 Abogada. Docente investigadora. Facultad de Ciencias Jurídicas de la Universidad de Manizales. Especialista en Derecho Administrativo. Magíster en Desarrollo Sostenible y Medio Ambiente. Estudiante doctorado en Desarrollo Sostenible.

Correo electrónico: cmunevar@umanizales.edu.co; claumunevar@gmail. com

4 Abogado. Docente investigador. Facultad de Ciencias Jurídicas de la Universidad de Manizales. Especialista en Derecho Constitucional. Magíster en Derecho. Doctorado (e) en Derecho.

Correo electrónico: rodrigogiraldo@ hotmail.com

Para citar este artículo use: Dávila, C., Munévar, C., \& Giraldo, R. (2017). Territorios margen y los mapas de la fragmentación. La creación de sujetos de desarrollo y sujetos de marginalidad. Civilizar Ciencias Sociales y Humanas, 17(32), 93-104. Doi: $10.22518 / 16578953.820$ 


\section{Introducción}

El presente artículo se realiza en el marco de la investigación "Conflictos y movimientos sociales de jóvenes en contextos de vulnerabilidad en la eco-región Eje Cafetero: hacía un proceso de constitucionalismo popular". El contexto de la reflexión se fundamenta desde las conclusiones de la investigación, alrededor de dos elementos: el territorio y sus sujetos. El primer elemento, asocia lo que los geógrafos, juristas, sociólogos y antropólogos han querido comprender como las dos imágenes que representan el territorio y el mapa (Fraser, 2008). Estos en algunos casos, han intentado identificar mediante el segundo, la existencia de un solo orden territorial, sin embargo, la evocación de estas dos imágenes empieza a representar tensiones producto de las luchas sociales a favor de la defensa del mismo. Estas luchas sociales se ven representadas por aquellos sujetos que se apartan de los modelos fijados según los lineamientos del desarrollo, el progreso y el crecimiento económico. En este sentido, la condición de sujetos de derechos queda rezagada a las condiciones políticas, económicas y sociales planteadas por los intereses del capital, las cuales esbozan nuevas identidades y nuevos escenarios de realización asociados a la vulnerabilidad, el desarrollo y la marginalidad.

El proyecto responde a una postura hermenéutico-comprensiva planteada desde la sociología jurídica. Lo hermenéutico viene a ser una visión de mundo, que desde la perspectiva del territorio conforman el presupuesto de análisis alrededor de la creación de categorías de sujetos de desarrollo y sujetos de marginalidad. Desde la sociología jurídica, el estudio se enfoca al análisis del territorio desde el orden macro-social, asociando su visión desde la complejidad y multiplicidad de las dimensiones socio-territoriales y espacio-temporales; y desde el orden micro-social, considerando el territorio no solo como una estructura física, sino una construcción humana, desplegada y realizada desde las acciones de los sujetos de derechos, construidos y de-construidos, desde los escenarios de desarrollo y marginalidad.

\section{Del Territorio del Capital a los Territorios Margen}

A través de la historia, el capitalismo ha demostrado la capacidad que tiene para construir no solo la historia del ser humano y de la naturaleza, sino el poder de organizar el territorio en el afán de superar los obstáculos que proponen los sujetos mediante las luchas sociales y de esta manera mantener su concepción hegemónica de mundo. El modelo capitalista no se ha tratado simplemente del mantenimiento del "interés económicocorporativo de la clase en el poder sino de hacer hegemónico su proyecto cultural" (Jiménez \& Novoa, 2014, p. 7).

Como es lógico esto ha recreado una serie de transformaciones no solo del modelo capitalista, sino que ha conducido a que las luchas sociales produzcan modificaciones en las concepciones de mundo, generando con esto tendencias en las reivindicaciones de sus derechos. En las décadas finales del siglo XX se recrean con claridad dichas tendencias, pues al lado de los derechos sociales, económicos y culturales aparece el territorio como valor agregado a las luchas de los movimientos sociales, los indígenas, afros y excluidos de las ciudades empiezan a recrear una nueva clase de justicia denominada "justicia territorial", que no es otra cosa que el reclamo de hombres y mujeres de construir su propia territorialidad y territorialización ${ }^{1}$, dos categorías que entran en tensión con los intereses del Estado-nación, representado por el capital nacional y los intereses del capital transnacional.

Así, las dos caras del territorio, capital y movimientos sociales definen la complejidad y multiplicidad de las dimensiones socio-territoriales y espacio-temporales, lo anterior conduce a mirar al orden territorial en un momento histórico específico que muestra "la correlación 
de fuerzas presentes en la sociedad", la cuales expresan lo que Massey ha denominado como "geometrías de poder". Para Massey (2012) los efectos de la modernidad estableció en el mundo relaciones de poder/conocimiento, las cuales se ven reflejadas en la geografía que nació de antiguas geografías de "poderes coloniales y espacios colonizados" (p. 137). En este sentido, se considera al territorio no como una estructura física donde se desarrolla las relaciones y las tensiones sociales y se emplaza el modelo de desarrollo productivo del capital, sino que constituye una construcción humana, donde los sujetos desde sus valores y acciones inducen una materialidad y una subjetividad propia al territorio que lo hace histórico y dinámico, es decir, "un lugar que se construye, se de-construye y se re-construye" (Jiménez \& Novoa, 2014, p. 8).

De lo anterior resulta necesario dar inicio a una reflexión sobre el territorio. Para Lefebvre (2013) el territorio "es la materialización de la existencia humana", este significado conduce a la problematización no solo del concepto, sino de las realidades territoriales que presentan los Estados contemporáneos, puesto que para el mundo capitalista los espacios son fragmentados rompiendo con la totalidad del mismo. Es por eso por lo que se parte de la concepción que plantea Milton Santos (1996), en la cual contempla la naturaleza y la sociedad, entendiendo que el espacio es "un conjunto de sistemas de objetos y sistemas de acciones, que lo forman de modo inseparable, solidario y contradictorio" (p. 51).

Para Mançano (2011) por sistemas de objeto se comprenden "los elementos naturales y los objetos sociales, o los objetos producidos por mediación de las relaciones sociales, que modifican y transforman la naturaleza, lo que explica su indivisibilidad"2 (p. 25). Si se mantiene la idea de espacio de Santos y de Mançano se debe mantener el principio de que el territorio es una construcción a partir del "espacio geográfico y que el espacio es anterior al territorio" (Raffestin, 1993, p. 144).
Ahora bien, si los movimientos sociales y las empresas transnacionales al ser actores y sujetos necesitan construir espacios y territorios que garanticen su existencia, hay que preguntarse sobre la intencionalidad del sujeto, pues es esta la que "vincula al sujeto con el objeto y el pensador con el objeto pensado" (Santos, 1996, p. 74), así la intencionalidad de los sujetos que grafean el territorio debe ser entendida como "la propiedad del pensamiento y de la ideología mediante la cual el sujeto delibera, planea, proyecta la significación y, por consiguiente, la interpretación, se realiza mediante los procesos de producción del espacio y en la compresión de esos procesos" (Mançano, 2011, p. 26).

Por lo tanto, el espacio y el territorio son producidos por los movimientos sociales a la luz de relaciones de poder que les permite a los actores (Estado, movimientos sociales y capital) planear, deliberar, proyectar y dirigir sus intencionalidades frente a la producción de un orden territorial, puesto que el poder de significar e interpretar "expresa la intensión, la pretensión del sujeto por apropiarse del territorio desde un acto de construcción y significación" (Mançano, 2011, p. 26). En palabras de Massey (2012), los sujetos recrean el imaginario de lugares defendibles que no es otra cosa que dualidad espacial materializada en la libertad espacial y el derecho al propio lugar.

De este modo, los sujetos expresan un acto político que les permite la libertad de producir sus significaciones y representaciones que no son otra cosa que prácticas espaciales y territoriales. A partir de las representaciones los sujetos elaboran una triada conceptual compuesta por las prácticas espaciales y territoriales, las representaciones del espacio y el territorio, y los espacios y territorios de la representación, dándole a cada una de estas dimensiones un tipo de espacio y de territorio. Lefebvre (2013) presenta tres tipos de espacios: "el espacio percibido, el espacio concebido y el espacio vivido" (p. 15), categorías que pueden ser dadas para el territorio, es decir, si el espacio 
es anterior al territorio, se puede hablar de un territorio percibido, concebido y vivido ${ }^{3}$.

La relación de estos espacios y territorios como producción de los sujetos y actores se construye desde las tensiones entendidas como resistencias y pugnas. La sociedad capitalista, desde el poder del capital, creería que las resistencias serían resueltas a favor del espacio y el territorio concebido, sin embargo, el espacio y el territorio vivido, aquellos donde se "encuentran los lugares de la pasión y de la acción" (Lefebvre, 2013, p. 16), no se someten ante las acciones y pasiones del capital, lo cual contribuye a que no se pueda ver como un ejercicio de homogenización, sino que resalta la pluralidad del territorio.

\section{De los territorios de las resistencias a los territorios de las re-existencias}

Las nuevas formas de ordenar el territorio gestadas por los grupos que ejercen el dominio se ven confrontadas por procesos de resistencia social popular, si bien existen dichos procesos también hay que reconocer que son pocos a la luz de la crisis política y económica que enfrenta el Estado-nación colombiano, la producción de ordenes territoriales y espaciales a partir de la acumulación del capital ha permitido que dentro del territorio nacional se geste lo que Jiménez y Novoa (2014) han denominado como las "geografías de las resistencias populares", término acuñado como una nueva configuración en nuestra América, dada la incapacidad de los grupos dominantes de generar procesos de inclusión política, social y económica.

Lo anterior ha conllevado a las ciencias sociales a preguntarse por la necesidad del nacimiento del sujeto, puesto que el poder del capital ha vuelto a la construcción de ideologías que instauran gobiernos con ciertas características despóticas, como lo diría Touraine (2000) "recurren a la creación de comunidades encerradas en su tradición, en sus formas de organización social o en las creencias religiosas" (p. 201), además del miedo diseminado por los medios de comunicación con el único fin de someter las ideas revolucionarias del momento.

Si bien las sociedades están penetradas por el consumo, la producción y la comunicación, y estos tres elementos son tomados como formas de obtener libertad, el elogio al miedo termina siendo más poderoso que los antiguos nacionalismos; en términos de Touraine (2000), "fingir que una nación o que una categoría social tenga que elegir una categoría universalista, destructora, y la conservación de una diferencia cultural absoluta es una mentira demasiado gruesa como para no cubrir intereses y estrategias de dominación" (p. 201).

El empezar a reconocer la existencia de los territorios de las resistencias, como producción social de prácticas que tensionan las prácticas de la gubernamentalidad, es decir, las razones impuestas por el Estado mediante los derechos liberales y ahora desde el neoliberalismo, abre la posibilidad de ver al territorio no solo como uso, esto es, "desde su utilidad como recurso", sino también el territorio usado, esto es, "en su totalidad, como espacio que expresa las diversas maneras que tienen los sujetos de existir sobre el territorio" (Jiménez \& Novoa, 2014, p. 21).

De esta manera, el territorio usado es el territorio de la re-existencia, donde los seres humanos se transforman a partir de la construcción de la manifestación de sus territorialidades, es la puesta en escena de la subjetivación, entendiendo que esta es la "penetración del sujeto en el individuo y por consiguiente la transformación del individuo en sujeto" (Touraine, 2000 , p. 209). En este sentido, los territorios de re-existencia, no solo son la muestra de territorialidades en disputa, sino la correspondencia de la conducta personal y de los roles sociales, es decir, la entrada de la subjetivación en la defensa y en la construcción del territorio destruye el yo, como forma de resistencia al individualismo a través de valores que recaen en el territorio producto de las interacciones sociales y las acciones políticas de los sujetos. 
Para Touraine (2000) "el yo se quiebra: por un lado el sujeto y por el otro el sí mismo" (p. 209), es decir, el sí mismo (self) asocia la naturaleza con los objetos construyendo los espacios y por ende los territorios, así como el sujeto asocia individuo y territorio. Así, el sujeto construye prácticas territoriales en la medida que se propone objetivos, hacia los cuales debe estar dirigida una acción y la utilización calculada de unos medios, en términos de Foucault, la postura política del sujeto recrea la elección de unas determinadas estrategias que "permitan la eficaz articulación entre medios y fines o en su defecto, el uso de los efectos imprevistos para un reglamento de los propios fines" (Castro, 2015, p. 36).

De lo anterior se puede colegir que el individuo conduce la unidad del espacio, "mezclando la vida y el pensamiento, la experiencia y la conciencia" (Touraine, 2000, p. 207), mientras tanto, el individuo que se transforma en sujeto que se caracteriza por el paso del ello al yo, significaría la apropiación, el control sobre el territorio vivido, insertándose en las relaciones sociales que no son otras que las territorialidades que se encuentran en disputa.

Por lo tanto, las territorialidades en disputa implican la tensión, el conflicto y la confrontación frente al modelo de desarrollo impuesto por el modelo capitalista y frente al uso y ordenación del territorio, es decir, el individuo que es el sujeto mínimo, aquel que es explotado, dominado y expropiado de su territorio, al erguirse propone desde su territorialidad y territorialización, un nuevo uso y sentido de los territorios $\mathrm{y}$ un rechazo frente a la consideración de ser un sujeto de un desarrollo ajeno a sus propias formas de progreso, concentrado en la materialización de ese individuo, sin la consideración de sus propias identidades.

\section{Desarrollo y otras formas de desarrollo. La creación de nuevos sujetos}

El desarrollo no solo se ha consolidado como una invención teórica fruto del pensa- miento moderno y antropocentrista, sino que además ha fijado los estilos y formas de vida de las personas, apropiándose de los imaginarios e ideales sociales e instalando en ellos ideas racionalistas y los valores propios de la modernidad (Munévar \& Giraldo, 2015). No obstante, este discurso también ha perpetrado las políticas económicas de los países, cuyas finalidades y metas se han inscrito bajo los ideales del progreso impuesto por las lógicas del desarrollo; lógicas y políticas que explican "las razones que tuvieron tantos países para comenzar a considerarse subdesarrollados" y "cómo 'desarrollarse' se convirtió para ellos en problema fundamental [...]" (Escobar, 2007, p. 23).

En este sentido, el discurso desarrollista buscó trascender de la dimensión teórica a la dimensión legal. Las políticas económicas no podían solo depender de la voluntad de los gobiernos para adaptarse a ella; resultaba indispensable fijar modelos y sistemas de crecimiento económico que correspondieran a las finalidades propias del desarrollo, cuyo máximo respaldo lo constituyera la figura de la legalidad investida no solo de la validez normativa, sino de un mando de autoridad en cabeza del Estado. Como lo afirma Sousa (2010):

[...] Todo el Estado es de derecho y todo derecho es del Estado [...]. Es también una simetría muy problemática [...] porque afirma la autonomía del derecho con relación a lo político en el mismo proceso en que hace depender su validez del Estado (p. 106).

En este sentido, la vía legal ha pretendido "legitimarse" para estandarizar las políticas y estrategias de desarrollistas, que en su intento de reconocer las diferentes formas de desarrollo y vínculos con la naturaleza, ha fracasado, no solo al confundir las diferencias sustanciales entre la legalidad y la legitimación social ${ }^{4}$, sino también al intentar imponer de forma general y sin atender las especificidades de cada cultura o pueblo, los parámetros por los cuales un país alcanzará los índices de crecimiento económico y las metas de progreso; metas generalmente 
disfrazadas en discursos orientados a lo social y lo ambiental, tratando de corresponder a esa tautología definida por el desarrollo sostenible 5 .

Acompañados de estas contradicciones conceptuales y teleológicas, se suma el estigma generadoa las manifestaciones de otras formas de desarrollo que se oponen o contradicen a la única forma de progreso impuesta por las tendencias desarrollistas. Este tipo de manifestaciones luchan contra el reduccionismo que solo logra ver a través del crecimiento económico, medido bajo los parámetros de la utilidad, el desarrollo y progreso de los pueblos, ignorando la historia marcada por cada ideología y cosmovisión, que por ir en vías paralelas, difícilmente encajarán en la única teoría predicada por el desarrollo.

La existencia de otras formas de desarrollo, evidencian diferentes tipos de luchas $\mathrm{y}$ confrontaciones de sujetos que han sido marginalizados por esa estructura que materializa las formas de vida bajo el signo de la utilidad y que los quiere convertir en sujetos de desarrollo, fijando una relación indecidible entre la persona y el progreso, pero no como fin, sino como medio. Como lo manifiesta Moreno (2014), "colocar al ser humano en el centro del DS [Desarrollo Sostenible]"6 (p. 195), tiene unas implicaciones importantes en la compresión del concepto, toda vez que el ser humano es convertido como "piedra angular" en el discurso del desarrollo social. Moreno (2014, citando a Sen, 1997), establece que con referencia a la expresión de "capital humano", el autor lo define como un concepto que "se concentra en el carácter de agentes (agency) de los seres humanos, que por medio de sus habilidades, conocimientos y esfuerzos, aumentan las posibilidades de producción” (p. 196).

Esta noción de la persona, reconfigura su reconocimiento como un sujeto de derechos, para considerarlo como un sujeto del desarrollo, toda vez que, al examinar la carga lingüística del alcance de su definición, convierte su esencia y su espíritu en un signo de materialidad, valorado por los costos de una sociedad consumista, cuyo reconocimiento de daños, impactos o afectaciones pretenden trasformar al sujeto y a sus identidades.

La trasformación del sujeto no solo se genera desde su reconocimiento, sino también desde su estigmatización, toda vez que, quien no quiera sujetarse a los postulados del desarro1lo, será un enemigo del mismo; concepción política definida por Schmitt (1999), como amigo y enemigo, cuyo alcance de su significado "posee una estructura lingüística y lógica diferente dependiendo de las diversas lenguas y grupos lingüísticos" (pp. 134-135). Las estigmatizaciones pueden dar lugar a la creación de identidades, donde el "progreso, en resumen, ha dejado de ser un discurso que habla de mejorar la vida de todos para convertirse en un discurso de supervivencia personal" (Bauman, 2013, p. 27), y donde la identidad "se nos revela sólo como algo que hay que inventar en lugar de descubrir" (Bauman, 2010, p. 40).

Este tipo de redefinición del ser humano como sujeto de desarrollo, constituye el escenario perfecto para un modelo económico que más que satisfacer necesidades básicas, las inventa, pese a que muchas son de alcance inmaterial, el modelo económico pretende suplirlas por bienes materiales.

Una de las paradojas que encontramos al analizar, por ejemplo, la tesis de la supuesta "desmaterialización" de la economía [...], es que precisamente en las sociedades ricas se ha producido una tendencia creciente a satisfacer las necesidades no materiales a través del consumo material (o mejor, a intentar satisfacerlas, porque los satisfactores pueden ser "falsos satisfactores" que producen frustración) (Martínez \& Roca, 2001, pp. 18-19).

Dichos satisfactores han logrado tal fuerza que no solo se han materializado a través de políticas económicas y jurídicas, sino que lograron perpetrar los imaginarios e ideales de vida bajo la noción de una cultura occidentalizada, que 
busca alcanzar a costo de su propia identidad las metas fijadas por el desarrollo y que marginaliza y excluye a aquellos sujetos que luchan por mantener sus vínculos con la naturaleza y fijar a través de ella, sus propias formas de desarrollo y su propia construcción de territorio.

\section{Escenarios y sujetos de marginali- dad en contextos de vulnerabilidad.}

La vulnerabilidad humana es innata a la propia condición del existir. En tal sentido, es precisamente el acto de habitar el mundo el que hace de todos los sujetos que vivimos -incluidos los no humanos $-^{7}$, sujetos apreciables, es decir, que valemos la pena per se, porque somos valiosos por nuestra condición humana. No obstante, el hecho de nuestra condición innata como seres humanos también hace que seamos vulnerables por naturaleza. La vida en sí, es un asunto complejo de sobrellevar y por eso cada uno de nosotros, dependiendo de nuestras creencias, ideologías, culturas y formas de ser, somos universos autónomos e indiscernibles.

Ahora bien, los seres humanos nos tornamos expuestos ante las inclemencias del mundo y de la vida, sobre todo, en sociedades marcadas por el temor, la incertidumbre y la exposición. Dicha situación se caracteriza por albergar una sociedad del riesgo, entendida por Beck (2002) como: "un peculiar estado intermedio entre la seguridad y la destrucción" (p. 215).

Naomi Klein (2007), ha denominado a la sociedad del riesgo como la "Doctrina del Shock", y la ha descrito como la existencia de una falta de empatía de ciertos sectores u oligopolios empresariales por la humanidad. Al respecto, dice que:

En apenas unos años, el complejo ha extendido su presencia en el mercado bajo distintas y cambiantes formas: desde las luchas contra el terrorismo hasta las misiones de paz internacionales, desde la seguridad municipal hasta la reacción con motivo de los desastres naturales. El objetivo último de las corpora- ciones que animan el centro de este complejo es implantar un modelo de gobierno exclusivamente orientado a los beneficios (que tan fácilmente avanza en circunstancias extraordinarias) también en el día a día cotidiano del funcionamiento del Estado; esto es privatizar el gobierno (p. 35).

No obstante, la vulnerabilidad existencial, diríamos, normal, forma parte de la vida misma, incluso, encuentra sentido en nuestras propias catarsis donde nos enfrentamos a temores y falencias. Sartre (1947) resume el existencialismo en la siguiente frase: "Así, el existencialismo se aferra a la idea de una naturaleza humana, pero esta vez no es una naturaleza orgullosa de sí misma, sino una condición temerosa, incierta y desamparada" (p. 96).

Entendiendo lo anterior, al contrario de la vulnerabilidad natural, encontramos otra de carácter superficial o propicia. Esta se desarrolla igualmente en contextos de habitar en el mundo, surge igualmente a partir de la idea de la simple exposición, pero adicionalmente, no solo somos vulnerables por existir, sino que también lo somos cuando nos conducen a escenarios de vulnerabilidad. En este último aspecto, no hablamos de un asunto de direccionamiento propio de la vida, sino de agentes externos que generan entornos para crear artificialmente la vulnerabilidad. Es así pues que se deben señalar a los responsables de esa "vulnerabilidad propiciada". Para efectos de este artículo, los propiciadores, autores intelectuales o generadores de la vulnerabilidad, pueden ser múltiples, conscientes o no. Estos, es decir, los arquitectos vulneradores, son diversos, actúan en la psique de los sujetos a partir de una aparente aceptación, en tanto los sujetos vulnerables o vulnerados, parecen autónomos y con plena consciencia de su libre albedrío, sin embargo, voluntaria o involuntariamente -en los peores casos- se pretermiten los referentes de dignidad, los derechos humanos, precisamente allí donde ocurren las peores exacciones.

Ahora bien, partiendo del concepto de vulnerabilidad viene la pregunta: ¿Por qué el ser 
humano y social se siente vulnerable? La respuesta a este interrogante tiene claras perspectivas de orden psicológico o psicoanalítico, que prima facie no interesan por el momento en este análisis, pues la respuesta que se quiere generar es de orden socio-político. La hipótesis que se generará en el presente estudio parte del presupuesto que la mencionada vulnerabilidad -tanto la natural como la artificial-, tienen su génesis en la marginalidad; entendiendo por esta, una suerte de abandono $u$ ostracismo voluntario de sujetos que se auto marginan, en un ejercicio bien de "humanofobia" - en los casos más extremos-, o simplemente no se sienten cómodos en el mundo que habitan, se asimilan más libres en marginalidad. No obstante, la marginalidad como un escenario de conflicto (armado, social, político, ambiental, etc.) plantea retos distintos, pues se constituye en un campo de violencia, imposición y saqueo. Es pues allí donde aparece un problema, cuando se margina al pobre, al opositor, al otro.

Respecto a la perspectiva social del concepto de marginalidad, Campos (1971) establece que su origen tiene lugar en los "asentamientos urbanos periféricos a las grandes ciudades [...] y que carecían a simple vista de las más mínimas condiciones de habitabilidad" (p. 75). No obstante, como lo establece el mismo autor, condiciones similares se encontraban en los centros de las ciudades, dando lugar al concepto de "poblaciones marginales, refiriéndose a todos aquellos agrupamientos humanos que estaban en una situación de privación, respecto de los sectores más acomodados de la sociedad" (p. 75). Sin embargo, dichas condiciones de privaciones, no resultaban exclusivas de los sectores urbanos,

[...] la población rural que presentaban características semejantes o peores a las que se podían encontrar en los asentamientos que rodeaban a las ciudades. Fue así como se percibió que la marginalidad estaba íntimamente relacionada con la falta de participación de los individuos, tanto en lo que hacía a la toma de decisiones como a la posesión de bienes (p. 75).
Buena parte del análisis acerca del concepto de la marginalidad ausculta algunas razones del concepto de ciudadanía, no desde la perspectiva tradicional occidental y jurídica institucional, como algo bondadoso, sino más bien como un discurso carente de respeto a la alteridad, poco altruista y ególatra, que discurre en las tramoyas legislativas. La situación del marginal (el no ciudadano), independientemente de su nacionalidad, su calidad de trashumante allende a la comunidad de naciones en los tiempos del capitalismo y la globalización, es antagónica con el concepto de ciudadanía, que es claramente excluyente y humanamente discriminatoria del humano no legalizado, como si este, el pseudociudadano, fuera un enfermo (positivismo biológico). Así las cosas, aquel que aun teniendo cédula de ciudadanía al interior del país, se entiende como un perseguido, un marginal, un invisible, una suerte de extraterrestre etiquetado previamente por un software perverso llamado ley.

En relación con la marginalidad, se puede entender un fenómeno inmanente al sistema capitalista y se engendra en el mismo, luego, la marginalidad es un proceso apenas natural en este tipo de sociedades de consumo y de intercambio de bienes y servicios. Al respecto se dice que:

Para la perspectiva crítica (asociada a la corriente de pensamiento histórico-estructural), la "marginalidad" está inserta en la estructura productiva de la sociedad; por lo tanto, esta problemática debe ser entendida como un fenómeno estructural y estable de la sociedad capitalista, en virtud del cual un sector importante de la población está al 'margen' o en 'el margen' del sistema social 'a causa del capitalismo'. [...] Esta situación social no permite que dicha población pueda gozar plenamente de los beneficios que genera la riqueza social: educación, vivienda, salud, etc. (Enríquez, 2007, p. 63).

Entendiendo que existen escenarios de marginalidad, también es cierto que dichos 
lugares $^{8}$ no serían posibles sin aquel sustrato fundamental que los hace posibles, es decir, sin los sujetos, pues son estos quienes visibilizan los escenarios de marginalidad desde el punto de vista de la existencia, de los sentidos, del vivir. Sujeto entendido como aquel ser humano que se conoce a partir de sus relaciones sociales, no simplemente quien se autoconstruye a partir de sus solipsismos y referentes de identidad.

Un sujeto en contexto de pobreza, es pues susceptible de constituirse en marginal; al respecto, Campos (1971) menciona lo siguiente:

Íntimamente asociada a este enfoque de la marginalidad, está la noción de la pobreza. Más aún, para determinados autores es esta condición la que determina a distintas condiciones como marginales. Para Welnes Benjamin, por ejemplo, la pobreza, “... sigue siendo el único criterio objetivo a que tiene derecho la experiencia directa y que autoriza tal vez todas las interpretaciones e inferencias que jalonan la literatura sociológica sobre el tema" (pp. 77-78).

Ahora bien, en tal sentido, un sujeto marginal es aquel cuyos espacios son los que ocupa en las periferias y las semiperiferias, es decir, quien no posee los mínimos derechos existenciales y humanos, que se desvirtúa superficialmente, por otros, siendo a su vez etiquetado como un desarraigado, un marginal, un invisible. Dicha deconstrucción no se da solo de sujeto a sujeto, sino que en esto juega un papel preponderante adicional, el sistema económico y político con todas sus cargas históricas e incidencias en sociedades contemporáneas marcadas por el caos. Al respecto, Díaz (1997) habla de una sinrazón histórica y reseña como uno de los componentes intrínsecos de la perversión neoliberal de que "“el derecho al desarrollo es una excrecencia de la mentalidad tercermundista' (Peter Berger). Sin embargo, esta actitud despectiva y depredadora frente al Tercer Mundo, se contradice con el principio de cohesión económica y social dentro de los países desarrollados" (p. 540).

\section{Conclusiones}

Así las cosas, podemos concluir que, aunque la novedad del capitalismo en la geopolítica de la globalización radique en la capacidad que tiene éste en la acumulación por desposesión, los territorios de la re-existencia plantean luchas urbanas y agrarias que trazan nuevas propuestas de ordenes territoriales, confrontando la imposición de orden que instaura el Estado-nación y el poder del capital. La transformación del territorio no solo debe ser vista como la simple evolución de un espacio físico, sino como la transformación del individuo a sujeto, donde este último impugna los procesos de asimetría que tienden a profundizarse con la arremetida usurpadora de las prácticas capitalistas y donde su identidad como sujeto no son fijadas por los parámetros de los modelos de desarrollo.

Los territorios que emergen dentro del Estado colombiano, se enfrentan a resistencias en donde los movimientos y las organizaciones sociales sustentan sus luchas de sus territorialidades históricas, es decir, las construidas desde las genealogías territoriales, entendiendo que estas son la oposición a los proyectos de saberes, del ser y del poder basados en la jerarquía de los poderes propios del capital. En palabras de Castro (2008): "una especie de tentativa de liberar de la sujeción a los saberes históricos, es decir, de hacerlos capaces de oposición y de lucha contra la coerción de un discurso teórico, unitario, formal y científico" (p. 37). Coerción no solo amparada en la legalidad de las normas, sino en la fuerza vinculante en la identidad del individuo, al cual absorbe o marginaliza.

Se puede concluir entonces que el concepto de marginalidad guarda una estrecha relación con lo sistémico, es decir, obedece más -por lo menos inicialmente- a causas estructurales de orden macro que a aspectos relacionados con las interacciones sociales o el comportamiento cotidiano de los individuos en contextos reales, por lo menos en el plano social. Sin embargo, 
se desprende de allí, de las neosociedades posindustriales y capitalistas, pues son estas las que llevan a explicaciones tanto de los sistemas productivos como del habitar en el mundo. Ese universo conflictivo, donde desde lo cotidiano se empieza a categorizar o etiquetar bajo " $\mathrm{X}$ " o "Y" conceptos. Al respecto, lo que hacen el cine, la televisión y en ocasiones la literatura, es llevar las relaciones del conflicto armado desde la quimera social del "sueño americano" que esa sociedad posfordista ofrece, la misma que lleva al sujeto marginal a una sin salida, al plano del amigo-enemigo, en un reduccionismo schmittiano que no atiende a causas de orden estructural sino a simples emotivismos acendrados en la venganza. Esos escenarios del esnobismo y la egolatría, alimentan de forma fatal la pobreza como el primer rasgo descriptivo, a su vez que el más espeluznante de eso denominado marginalidad.

\section{Notas}

1 Se debe entender por territorialidad como la dimensión espacial de los actores y valores que estos atribuyen al espacio intervenido y la territorialización como al conjunto de acciones implementadas por estos actores en nombre de sus valores (Monnet, 2010, p. 27).

2 ParaMançano(2011), "la indivisibilidad es una palabra clave porque une los sistemas de objetos con los sistemas de acciones de modo contradictorio y solidario, lo que se expresa en los conflictos generados por las diferentes intencionalidades" (p. 25). En nuestro caso, la intencionalidad del capital y las de los movimientos sociales en la creación de sus espacios, no podemos separar los sistemas de acciones y de objetos producidos por estos, pues es allí donde se marcan las tensiones producidas por los sujetos que entablan relaciones sociales, es decir, el espacio se construye como campos que se mantienen en movimiento, construyendo historia, produciendo no solo espacialidad, sino diferentes territorialidades y por ende territorios.
3 "El espacio percibido debe entenderse como el espacio de la experiencia material, que vincula la realidad cotidiana (uso del tiempo) y la realidad urbana y agraria (redes y flujos de personas, mercancías o dinero que se asientan en y transitan el espacio), englobando tanto la producción como la reproducción social. El espacio concebido es el espacio de los expertos, los científicos, los planificadores, el espacio de los signos, de los códigos de ordenación, fragmentación y restricción. El espacio vivido, es el espacio de la imaginación y de lo simbólico dentro de una existencia material, es el espacio de usuarios y habitantes, donde se profundiza en la búsqueda de nuevas posibilidades de la realidad espacial" (Lefebvre, 2013, p. 16).

4 Como lo expresa Durán (1997): “No se puede omitir que el derecho no se agota en el derecho positivo [...] sino también desde la legitimidad del contenido de las normas jurídicas; y también desde la aceptación de dichas normas por parte de los miembros del grupo" (p. 33).

5 Strange y Bayley (2012), definen por desarrollo sostenible como aquel que "cubre las necesidades del presente sin poner en riesgo la capacidad de las futuras generaciones de cubrir las propias. [...] Un elemento central del desarrollo sostenible es la necesidad de considerar 'tres pilares' en conjunto: la sociedad, la economía y el medio ambiente" (pp. 32-35).

6 La expresión "centro", no solo hace referencia a la perspectiva humanista que "erige al hombre como valor supremo al que habrán de supeditarse todas las cosas" (Lezama, 2014, p. 119), sino como un medio para alcanzar los fines de progreso que son fijados por los parámetros del mercado y la utilidad.

7 Al respecto menciona Zaffaroni (2012) que: "[...] Aunque el spencerianismo contemporáneo no lo diga expresamente $\mathrm{y}$ aunque oculte con sumo cuidado el nombre mismo de Spencer-que en tiempos actuales sería poli- 
ticamente incorrecto- no es posible negar que sus consecuencias últimas serían que los verdaderos titulares plenos de derechos sólo pueden ser los humanos superiores, aunque de esa condición se deriven obligaciones éticas de piedad para los inferiores y los animales, pero sin exagerar, porque la filantropía exagerada puede llevar a privar los inferiores del derecho a hacerse fuertes en la lucha por la supervivencia” (p. 42).

${ }^{8}$ Acerca de los lugares, dice Marc Auge (1992) lo siguiente: "El lugar y el no lugar son más bien polaridades falsas: el primero no queda nunca completamente borrado y el segundo no se cumple nunca totalmente: son palimpsestos donde se reinscribe sin cesar el juego intrincado de la identidad y de la relación. Pero los no lugares son la medida de la época, medida cuantificable y que se podría tomar adicionando, después de hacer algunas conversiones entre superficie, volumen y distancia, las vías aéreas, ferroviarias, las autopistas y los habitáculos móviles llamados 'medios de transporte' (aviones, trenes, automóviles), los aeropuertos y las estaciones ferroviarias, las estaciones aeroespaciales, las grandes cadenas hoteleras, los parques de recreo, los supermercados, la madeja compleja, en fin, de las redes de cables o sin hilos que movilizan el espacio extraterrestre a los fines de una comunicación tan extraña que a menudo no pone en contacto al individuo más que con otra imagen de sí mismo" (pp. 85-86).

\section{Referencias}

Auge, M. (1992). Los no lugares. España: Gedisa.

Bauman, Z. (2010). Identidad. Argentina: Editorial Losada.

Bauman, Z. (2013). La cultura en la modernidad líquida. México: Fondo de Cultura Económica.

Beck, U. (2002). La sociedad del riesgo global. España: Siglo XXI Editores.
Campos, J. (1971). El concepto de marginalidad social en América Latina. Revista Integración, 8, 75-95. Recuperado de http://www20.iadb.org/intal/catalogo/ Revista_Integracion/documentos/e_REVINTEG_008_1971_Estudios_03.pdf

Castro, S. (2008). Genealogías de la colombianidad. Colombia: Instituto Pensar; Pontificia Universidad Javeriana.

Castro, S. (2015). Historia de la gubernamentalidad. Razón de Estado, liberalismo y neoliberalismo en Michel Foucault. Colombia: Siglo del Hombre Editores.

Díaz, P. (1997). Estado y Tercer Mundo. El Constitucionalismo. Colombia: Temis.

Durán, P. (1997). Notas de Teoría del Derecho. España: Universidad Jume I Castello.

Enríquez, P. (2007). De la marginalidad a la exclusión social: un mapa para recorrer sus conceptos y núcleos problemáticos. Fundamentos en Humanidades, 8(15), 57-88.

Escobar, A. (2007). La invención del tercer mundo. Construcción y deconstrucción del desarrollo. Venezuela: Fundación Editorial El Perro y la Rana.

Fraser, N. (2008). Escalas de la Justicia. Barcelona: Heder.

Jiménez, C., \& Novoa, E. (2014). Producción social del espacio: el capital y las luchas sociales en la disputa territorial. Colombia: Ediciones Desde Abajo.

Klein, N. (2007). La doctrina del shock. España: Booket.

Lefebvre, H. (2013). La producción social del espacio. Madrid: Capitán Swing. 
Lezama, J. (2014). Teoría social, espacio y ciudad. México: El Colegio de México.

Mançano, B. (2011). Territorio, teoría y política. En G. Calderón \& E. Hernández (Coords.), Descubriendo la espacialidad social desde América Latina. Reflexiones desde la geografia sobre el campo, la ciudad y el medio ambiente (pp. 21-51). México: Ítaca.

Martínez, J., \& Roca, J. (2001). Economía ecológica y política ambiental (2a ed.). México: Fondo de Cultura Económica.

Massey, D. (2012). Un sentido global de lugar. Barcelona: Editorial Icaria.

Monnet, J. (2010). Territorio reticular. Colombia: Universidad de Caldas.

Moreno, M. (2014). Génesis, evolución y tendencias del paradigma del desarrollo sostenible. México: Editorial Miguel Ángel Porrúa.

Munévar, C., \& Giraldo, R. (2015). Desarrollo y derechos humanos: incidencias, aproximaciones y tendencias. Revista Jurídicas, 12(1), 25-43.
Raffestin, C. (1993). Por una geografia do poder. São Paulo: Ática.

Santos, M. (1996). A natureza do espaço. São Paulo: Huitec.

Sartre, J. (1947). El existencialismo es un humanismo. Argentina: Sur.

Schmitt, C. (1999). El concepto de lo político. España: Alianza.

Sousa, B. (2010). Refundación del Estado en América Latina. Perspectivas desde una epistemología del sur. Colombia: Siglo del Hombre Editores; Universidad de los Andes.

Strange, T., \& Bayley, A. (2012). Desarrollo Sostenible: integrar la economía, la sociedad y el medio ambiente. México: OCDE; Instituto de Investigaciones Económicas, UNAM.

Touraine, A. (2000). Critica de la modernidad. México: Fondo de Cultura Económica.

Zaffaroni, E. (2012). La pachamama y el humano. Argentina: Ediciones Colihue. 